\title{
Analysis of histological subtypes of incident lung cancer among Eldorado uranium workers
}

\author{
$1^{*}$ Lydia B. Zablotska \\ ${ }^{1}$ School of Medicine, University of California, San Francisco, San Francisco, CA,94143, USA
}

Exposure to radon decay products (RDP) is one of the best-studied carcinogenic phenomena in radiation epidemiology [1]. Epidemiological studies, primarily of underground miners, show increases in lung cancer risk from exposure to RDP [1,2]. Only a few studies have been published on the radiation risks of specific histological subtypes of lung cancer [3-6]. Radon exposure in uranium miners seems to be especially related to small cell and squamous cell lung cancer [4]. The latter one follows the pattern of distribution of radon decay products in the bronchial epithelium, from which it originates. Tobacco smoking has been shown to be more strongly associated with squamous cell and small cell carcinoma than with adenocarcinoma $[4,7,8]$. The manner of interaction between smoking and RDP exposures in causing lung cancer is a matter of debate $[3,9$, $10]$.

This study assessed the relationship between RDP exposure and lung cancer incidence in a cohort of 16,770 Eldorado uranium workers from Canada first employed in 1932-1980 and followed up for cancer incidence through the Canadian Incidence DataBase (CIDB) during 1969-1999. The current analysis was based on substantially revised identifying information and RDP dosimetry for workers from the Beaverlodge and Port Radium uranium mines, and from a radium and uranium refinery and processing facility in Port Hope. In brief, the annual mean RDP exposure in working level months (WLM) was calculated by summing over the WL measurements available for each type of workplace, the proportion of workers in each occupation and the proportion of time spent in each type of workplace by workers in each occupation. Workplace RDP concentration measurements were supplemented by data on seasonal mine ventilation rates, building air volumes and air exchange rates. The current study also has information on individual $\gamma$-ray doses for all cohort subjects. Personal $\gamma$-ray doses were calculated from the average dose-rates and time on the job and expressed in millisieverts $(\mathrm{mSv})$ for workers who did not wear a personal dosimeter.

Each individual contributed person-years at risk from the later of the date of hire or the start date of follow-up, January $1^{\text {st }}, 1969$. 'Exit date' was defined as December $31^{\text {st }}, 1999$, the date of cancer diagnosis or death, or the last date known alive (defined as date of last employment or contact), whichever occurred earlier.

The initial set of analyses was based on external comparisons of the cohort with the general Canadian population. Observed and expected values were used to estimate standardized incidence ratios (SIR) by means of indirect standardization. Expected values were derived from Canadian population cancer incidence (1969-1999) rates, adjusted for

Corresponding author: Lydia.Zablotska@ucsf.edu 
sex, age and calendar year at risk. In addition, we separately estimated SIRs for major histological subtypes of lung cancer (squamous cell, small cell, adenocarcinoma, other) for 1985-1999. Poisson regression was used to estimate radiation risks of lung cancer (together and separately for major histological subtypes) from RDP exposures and gamma-ray doses and to investigate possible modifying effects of time since exposure, exposure rate and age at risk. All analyses were adjusted for age at risk (15-19, 20-24 . 85-100 years), calendar year at risk (1969-1974, 1975-1979... 1995-1999), employment site (Port Hope, Port Radium, Beaverlodge, "other sites"), total duration of employment (0-6 months, 6 months + ), age at first exposure, cumulative exposure, and years since first exposure. All RDP exposures and $\gamma$-ray doses were lagged by 5 years to account for the latency period between exposure and lung cancer incidence. Regression parameters, 95\% confidence intervals $(95 \% \mathrm{CI})$ and $\mathrm{p}$-values were estimated using the maximum likelihood method in the AMFIT module of the EPICURE software [11]. Tests of statistical significance were based on the likelihood ratio test and all p-values were two-sided.

Incidence rates of lung cancer were significantly higher compared to the Canadian national calendar time-, sex- and age-specific rates. SIRs increased with increasing RDP exposures in a dose-dependent way. Sub-group analyses showed that significantly elevated SIRs were observed only for workers from the Beaverlodge and Port Radium facilities (uranium miners), whiles SIRs for workers from Port Hope facility (uranium millers) were elevated but not statistically significant and SIRs for workers employed at "other sites" were significantly lower compared to the Canadian general population rates of lung cancer.

Most workers were male ( $\mathrm{N}=15,336,91.6 \%$ of the cohort), so all further analyses were restricted to "all male workers." During follow-up, 626 lung cancers were diagnosed in the cohort (33\% squamous cell, $16 \%$ small cell, $18 \%$ adenocarcinoma and $33 \%$ other subtypes). We observed a monotonic increase in risk for lung cancer incidence, with the highest risks seen in the highest RDP exposure category. The estimated excess relative risk for RDP exposures was positive and statistically significant $(\mathrm{p}<0.001)$, with no estimated differences in the dose-response between different facilities ( $\mathrm{p}$ heterogeneity $=0.38$ ). Estimated radiation risks for squamous cell subtype were significantly different from risks for all other subtypes combined ( $\mathrm{p}$ interaction $<0.05$ ). Radiation risks for small cell carcinoma and adenocarcinoma were also significantly increased, but with lower point estimates. We also examined effect modification by time since exposure $(p<0.001)$, exposure rate and age at risk (both $\mathrm{p}>0.1$ ). Gamma-ray doses did not significantly improve the fit of the model with RDP exposures.

In summary, the current study supports the use of BEIR VI-type models to predict future risk of lung cancer from past and current RDP exposures. Radiation risks of lung cancer differ by histological subtype. Further studies are needed to better understand the association between affected tissues and radiation risks of lung cancer. 


\section{References}

1. NRC: Committee on Health Risks of Exposure to Radon. Health effects of exposure to radon. Biological Effects of Exposure to Ionizing Radiation: BEIR VI. (National Research Council (NRC) ed. Washington, DC: National Academies Press; (1999)

2. M. Al-Zoughool, D. Krewski. Health effects of radon: A review of the literature. Int J Radiat Biol. 85(1):57-69; (2009)

3. H. Egawa, K. Furukawa, D. Preston, S. Funamoto, S. Yonehara, T. Matsuo, S. Tokuoka, A. Suyama, K. Ozasa, K. Kodama, K. Mabuchi. Radiation and smoking effects on lung cancer incidence by histological types among atomic bomb survivors. Radiat Res. 178(3):191-201; (2012)

4. M. Kreuzer, K. M. Muller, A. Brachner, M. Gerken, B. Grosche, T. Wiethege, H. E. Wichmann. Histopathologic findings of lung carcinoma in German uranium miners. Cancer. 89(12):2613-21; (2000)

5. D. Taeger, A. Fritsch, T. Wiethege, G. Johnen, A. Eisenmenger, H. Wesch, Y. Ko, S. Stier, K. Michael Muller, T. Bruning, B. Pesch. Role of exposure to radon and silicosis on the cell type of lung carcinoma in German uranium miners. Cancer. 106(4):881-9; (2006)

6. L. Tomasek, V. Placek. Radon exposure and lung cancer risk: Czech cohort study. Radiat Res. 152(6 Suppl):S59-63; (1999)

7. S. A. Khuder. Effect of cigarette smoking on major histological types of lung cancer: a meta-analysis. Lung Cancer. 31(2-3):139-48; (2001)

8. B. Pesch, B. Kendzia, P. Gustavsson, K. H. Jockel, G. Johnen, H. Pohlabeln, A. Olsson, W. Ahrens, I. M. Gross, I. Bruske, et al. Cigarette smoking and lung cancer--relative risk estimates for the major histological types from a pooled analysis of case-control studies. Int J Cancer. 131(5):1210-9; (2012)

9. K. A. L'Abbe, G. R. Howe, J. D. Burch, A. B. Miller, J. Abbatt, P. Band, W. Choi, J. Du, J. Feather, R. Gallagher, et al. Radon exposure, cigarette smoking, and other mining experience in the beaverlodge uranium miners cohort. Health Phys. 60(4):489-95; (1991)

10. K. Leuraud, M. Schnelzer, L. Tomasek, N. Hunter, M. Timarche, B. Grosche, M. Kreuzer, D. Laurier. Radon, smoking and lung cancer risk: results of a joint analysis of three European case-control studies among uranium miners. Radiat Res. 176(3):375-87; (2011)

11. D. L. Preston, J. H. Lubin, D. A. Pierce, M. E. McConney: EPICURE User's guide. Seattle, WA: Hirosoft International Corporation; (1993) 